\title{
MAPEAMENTO TÊMPORO-ESPACIAL DAS QUEIMADAS NO PARQUE NACIONAL DA SERRA DA CANASTRA E SUAS RELAÇÕES COM AS ZONAS DE PLANEJAMENTO
}

\author{
Cassiano Gustavo Messias ${ }^{(a)}$, Marcos Cesar Ferreira $^{(b)}$ \\ (a) Departo. de Geografia / Instituto de Geociências, Universidade Estadual de Campinas, macferre@uol.com.br \\ (b) Departamento de Geografia / Instituto de Geociências, Universidade Estadual de Campinas, \\ cassianomessiaslavras@gmail.com
}

Eixo: Geotecnologias e modelagem espacial em Geografia Física

\begin{abstract}
Resumo
Este trabalho tem como objetivo geral elaborar a cartografia têmporo-espacial das queimadas ocorridas no Parque Nacional da Serra da Canastra (MG), localizado a Sudoeste de Minas Gerais, nos últimos trinta anos. Além disso, identificar as áreas de maior recorrência dos eventos desta natureza, avaliando-as pelas três unidades de planejamento do parque: zona de amortecimento, zona regularizadae zonas não regularizadas. No desenvolvimento metodológico, foram obtidos produtos de sensores orbitais Landsat TM, ETM+ e OLI, entre 1984 e 2015, nos quais foram identificados e mapeados, anualmente, os polígonos de áreas atingidas pelo fogo. Calculou-se o Índice de Recorrência de Queimadas (IRQ), o qual indica o grau de repetições do evento no período de trinta anos. As zonas mais afetadas pelas queimadas trata-se das não regularizadas, seguidas pelas zonas regularizadas e de amortecimento. Os maiores IRQ foram identificados também nas zonas não regularizadas e os menores índices na zona de amortecimento.
\end{abstract}

Palavras chave: Queimadas; Landsat; Planejamento; Parque Nacional da Serra da Canastra; Unidades de Conservação.

\section{Introdução}

Recentemente tem havido significativa conscientização mundial pela necessidade de se buscarem técnicas voltadas ao desenvolvimento sustentável, visando a mitigação de prejuízos diretos e indiretos causados pelas queimadas (LIU, 2006). Mesmo beneficiando, em parte, ecossistemas adaptados ao fogo, os incêndios são fatores de perturbação. Incêndios catastróficos podem causar grandes danos a bacias hidrográficas, provocado pela redução da cobertura vegetal e alteração das características do solo (MILLER E YOOL, 2002).

Estudos comprovam que os incêndios florestais têm destruído grandes áreas de vegetação nativa no Brasil. De modo geral, algumas regiões são mais propensas à ocorrência de queimadas, como por exemplo, aquelas situadas em zonas climáticas cujo final do inverno é seco e que utilizam fogo na prática 
agrícola, como é o caso, do estado de Minas Gerais (LIMA, 2000). A grande ocorrência de incêndios pode ser uma grave ameaça, principalmente, para a conservação da biodiversidade e à manutenção de processos ecológicos em Unidades de Conservação (UC) no Brasil, visto que maioria destas áreas apresenta uma ou mais características de vulnerabilidade (MEDEIROS; FIEDLER, 2004). Na opinião de alguns brigadistas de Unidades de Conservação, há carência de infraestrutura, insuficiência no patrulhamento, falta de apoio da população vizinha às UC, atraso nas atividades de prevenção e insuficiência nos investimentos (PEREIRA et al., 2004).

O Parque Nacional da Serra da Canastra (PNSC), localizado a sudoeste de Minas Gerais, é um exemplo de UC cujo fogo é visto como uma das principais atividades conflitantes. As queimadas, de forma indiscriminada, ameaçam a preservação deste parque, cuja relevância está relacionada à grande beleza cênica, diversidade de fauna e flora do cerrado e presença de nascentes de importantes rios, como as dos rios São Francisco e Araguari (MMA; IBAMA, 2005).

Na extensão do PNSC, grande parte dos incêndios são de origem humana (MEDEIROS; FIEDLER, 2004). As queimadas criminosas são provocadas por insatisfação de moradores com a unidade de conservação, problemas fundiários ou até, desinformação (MMA;IBAMA, 2005). Proprietários de terra realizam ainda, queimadas entre dezembro e janeiro, com a finalidade de renovar o pasto e proteger suas áreas de grandes incêndios na estação seca (MISTRY; BIZZERRIL, 2011). Ademais, características naturais da paisagem tem papel fundamental na propagação do fogo no PNSC. O auge ou final da estação seca, quando se têm temperaturas elevadas, baixa umidade, ventos fortes e vegetação mais seca, propicia queimas de maior intensidade (MEDEIROS; FIEDLER, 2004).

Este trabalho tem como objetivo elaborar a cartografia têmporo-espacial das queimadas ocorridas no PNSC nos últimos trinta anos. Além disso, serão identificadas as áreas de maior recorrência dos eventos desta natureza, avaliando-as pelas três unidades de planejamento do parque: zona de amortecimento (ZA), zona regularizada (ZR) e zonas não regularizadas (ZNR).

\section{2. Área de estudo}

O PNSC está localizado a sudoeste do estado Minas Gerais, Brasil, nos municípios de São Roque de Minas, Sacramento, Delfinópolis, São João Batista da Glória, Capitólio e Vargem Bonita. Sua Zona de Amortecimento, além dos municípios já citados, inclui Alpinópolis, Cássia, Ibiaci, Passos e Piumhi (Figura 1). 


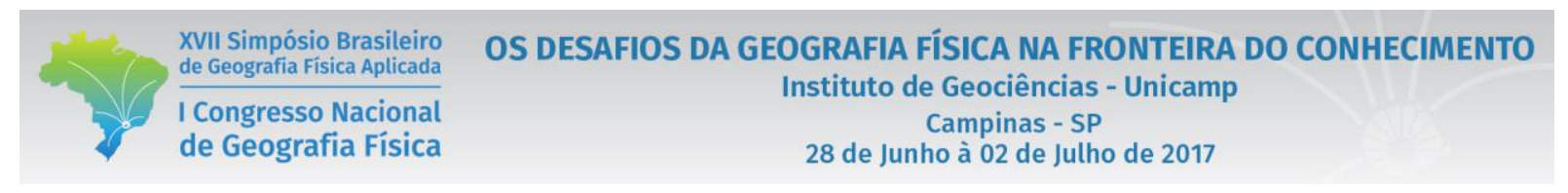

A criação desta UC se deu pelo decreto $\mathrm{n}^{0}$ 70.355, de 3 de abril de 1972, definindo-se uma área de 197.787ha. No entanto, apenas 71.525ha, localizados no Chapadão da Canastra, foram devidamente regularizados neste momento (IBDF, 1981). Tem-se atualmente, um total de 82.000ha regularizados, constando também fragmentos do Chapadão da Babilônia, mas sendo ainda distante da área inicialmente definida (MESSIAS, 2014). Já a ZA possui um perímetro de $1.493 .790 \mathrm{Km}$ ao redor do Parque e uma superfície de 269.513ha (MMA; IBAMA, 2005).

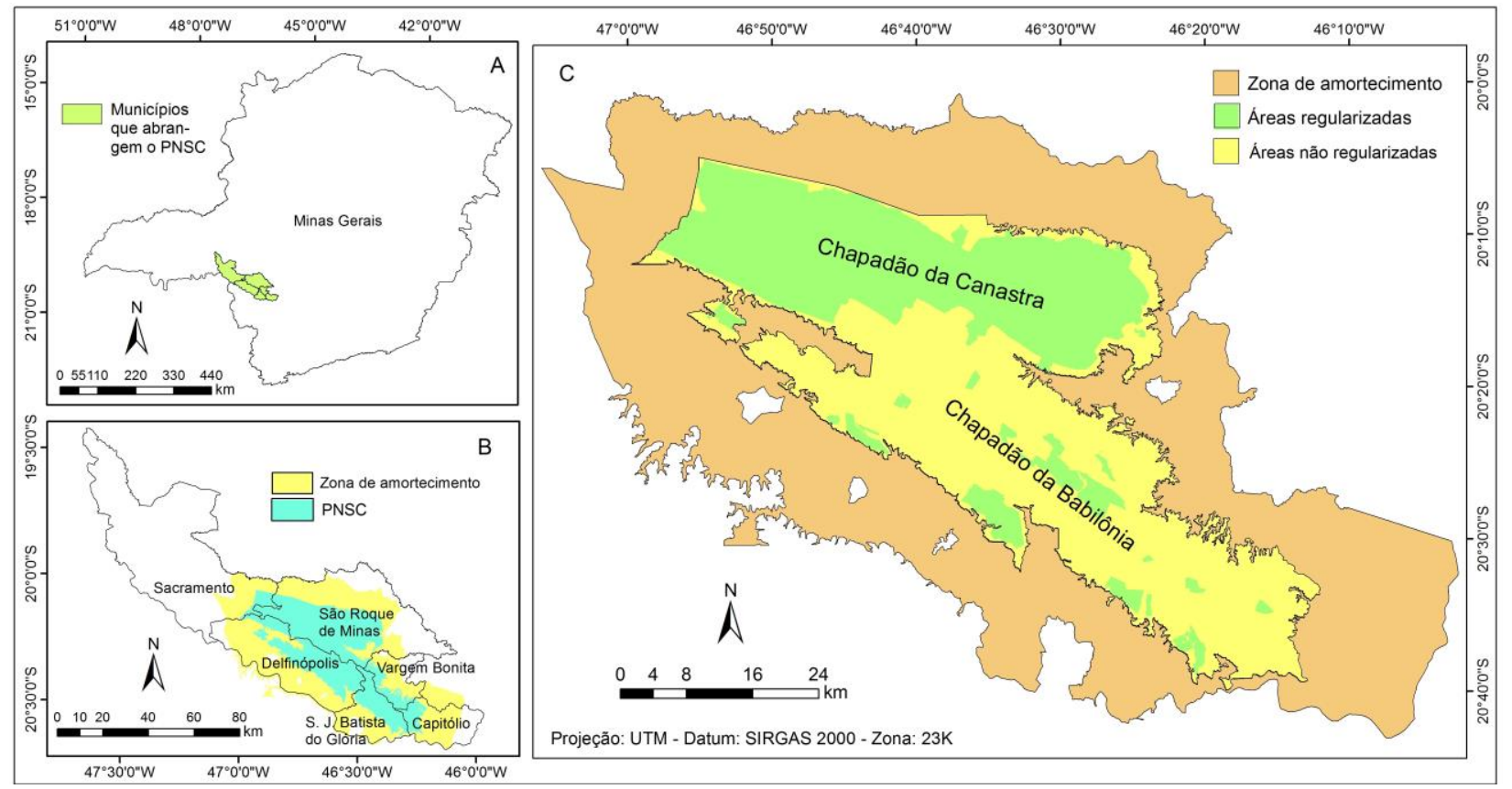

Figura 1 - Localização da área de estudo em escala estadual (A), municipal (B)e local (C).

\section{Material e métodos}

\subsection{Material}

Foram obtidos produtos de sensores orbitais Landsat TM, ETM+ e OLI, entre 1984 e 2015. Adquiriram-se o máximo possível de imagens para cada ano, considerando-se representativos os anos que possuem, pelo menos, três imagens de boa qualidade, distribuídas ao longo período seco ou início do chuvoso - quando ocorre maior número de queimadas. Por apresentarem grande interferência de nuvens nas imagens, os anos de 2003 e 2012 foram desconsiderados no mapeamento, por não serem representativos. Além disso, empregaram-se arquivos vetoriais, os quais estão descritos juntamente aos produtos de teledetecção na Tabela 1. 
Tabela 1 - Material cartográfico e produtos de sensores orbitais a serem utilizados na pesquisa.

\begin{tabular}{lcccc}
\hline \multicolumn{1}{c}{ Material cartográfico } & Órbita/ponto & Resolução & Ano & Executor \\
\hline Arquivo vetorial dos limites do PNSC & - & - & 2012 & ICMBio \\
Arquivo vetorial das zonas regularizadas do PNSC & & & 2013 & PNSC \\
Arquivo vetorial dos limites da ZA do PNSC & - & - & 2014 & PNSC \\
Imagens Landsat 5 / TM & $219 / 74$ e 220/74 & $30 \mathrm{~m}$ & 1984 a 2011 & NASA \\
Imagens Landsat 7 / ETM+ & $219 / 74$ e 220/74 & $30 \mathrm{~m}$ & 1999 a 2003 & NASA \\
Imagens Landsat 8 / OLI & $219 / 74$ e 220/74 & $30 \mathrm{~m}$ & 2014 a 2015 & NASA \\
\hline
\end{tabular}

\subsection{Metodologia}

\subsubsection{Pré-processamento de produtos Landsat}

No ArcGIS 10.1, geraram-se diferentes composições coloridas falsa cor: 7R/4G/3B e 7R/5G/4B (no caso de produtos TM e ETM+) e 5R/4G/7B e 7R/6G/5B (para OLI) e cor verdadeira: 3R/2G/1B (para produtos TM e ETM+) e 4R/3G/2B (para OLI). Executou-se a correção geométrica das imagens dos sensores TM e ETM+, pela ferramenta Georreferencing, tomando como base as imagens OLI, as quais são disponibilizadas corrigidas geometricamente. Por fim, fez-se o recorte da área de interesse, considerando os limites da zona de amortecimento do parque.

\subsubsection{Identificação e mapeamento de áreas queimadas}

Considerando-se que todas as características da superfície têm diferentes padrões de resposta espectral, há a possibilidade de se identificarem queimadas a partir do uso de produtos de sensores orbitais (SUNAR; ÖZKAN, 2001). Em uma composição colorida 7R/5G/4B, gerada por imagem Landsat 7 $\mathrm{ETM}+$, podem ser identificadas, visualmente, as áreas queimadas entre cores marrom intenso, marrom, cinza, laranja vermelha e vermelha pálida, o que depende do estágio da queimada (LIU, 2006).

Para cada ano da série temporal, gerou-se um documento no ArcGIS 10.1, onde foram inseridas todas as imagens referentes àquele ano, já pré-processadas. Essas imagens foram ordenadas por ordem crescente de data na tabela de conteúdo, a fim de se perceber como se deu a evolução do fogo entre uma imagem e outra de datas distintas. Utilizando uma imagem aleatória (Produto: TM; ID: LT52190741988240CUB001988; data: 27/08/1988), selecionou-se uma área amostral, na qual foi avaliada a ocorrência de queimadas e geraram-se chaves de interpretação, com a finalidade de facilitar a identificação e mapeamento das feições (Quadro 1). 


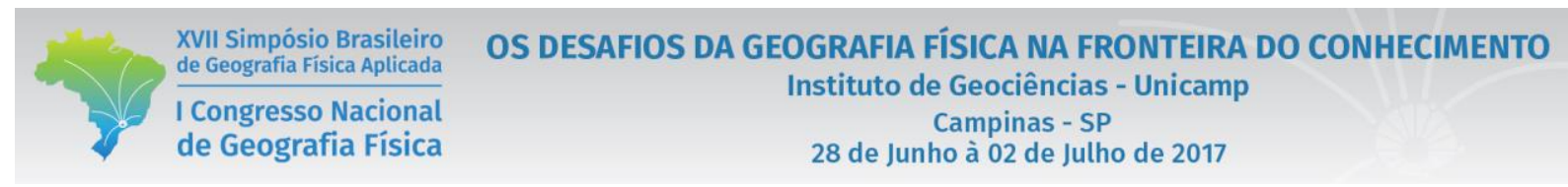

Para auxiliar o a identificação e garantir que todas as queimadas ocorridas no parque seriam mapeadas, geraram-se grades regulares de $5 \times 5 \mathrm{~km}$, as quais foram percorridas no sentido Sul-norte. Gerouse um arquivo em formato vetorial para cada ano da série temporal, utilizando modo de implantação polígono, no qual digitalizaram-se as queimadas ocorridas. A digitalização foi realizada em escala aproximada de 1:15.000, garantindo que somente pixels queimados fossem identificados, evitando selecionar pequenos pixels de outros usos não queimados, como pequenas matas e corpos d'água.

Após mapeados todos os anos, estes produtos foram utilizados na geração de mapas evidenciando a recorrência de queimadas, ou seja, quantas vezes as diferentes áreas foram incendiadas em todo o intervalo de tempo trabalhado, ou seja, em trinta anos. Para isto, os arquivos foram convertidos em formato matricial e reclassificaram-se os pixels, aplicando-se: valor 0, para os pixels em que não houve queimada; valor 1, para os que houve queimada.

Quadro 1 - Chaves de interpretação para a identificação de queimadas em produtos Landsat 5 TM

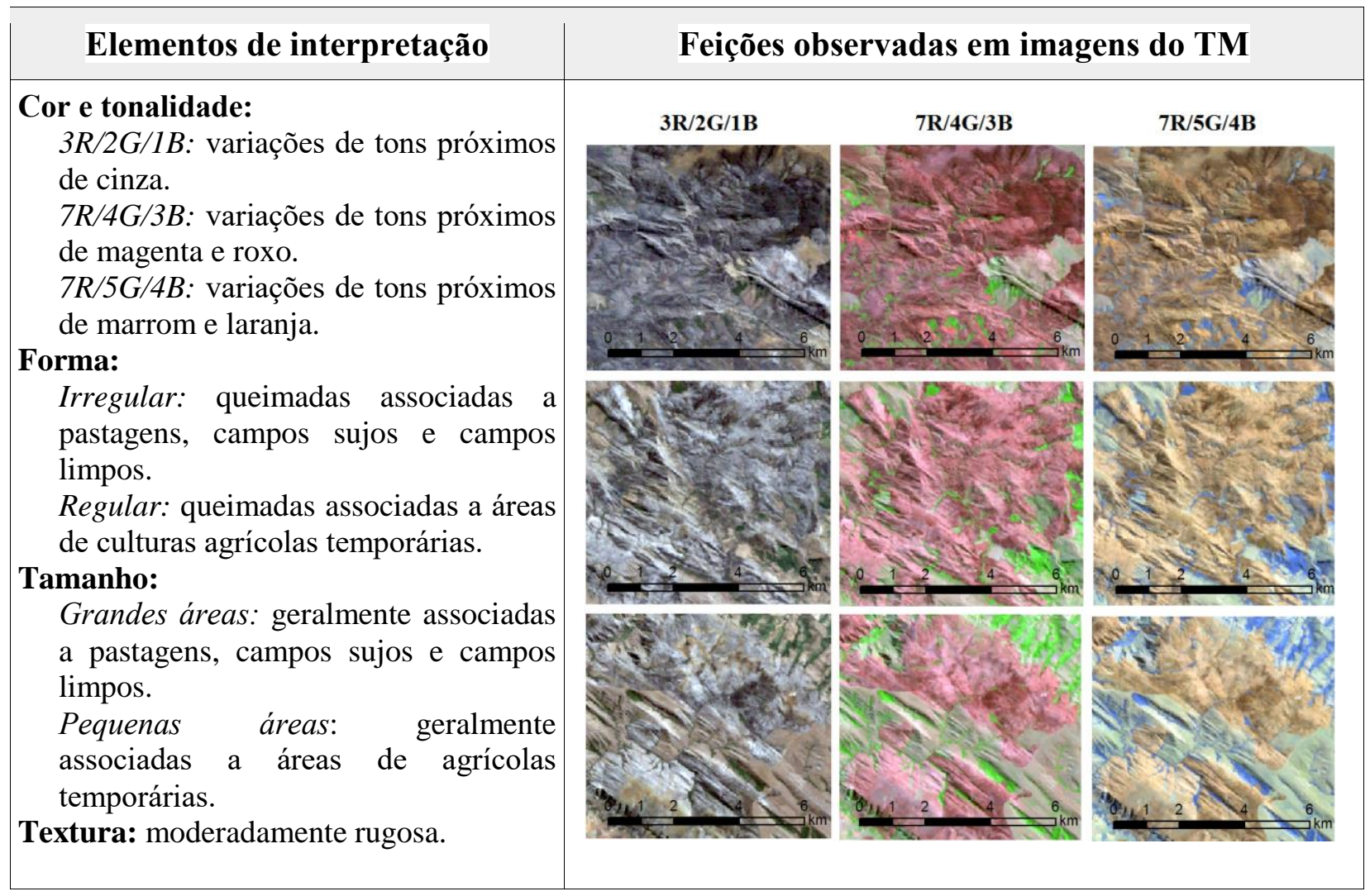

\subsubsection{Calculo do Î́ndice de Recorrência de queimadas $(I R Q)$}


Após mapeamento das queimadas nos trinta anos trabalhados, calculou-se o Índice de Recorrência de Queimadas (IRQ), o qual indica o grau de repetições do evento, em um determinado pixel, naquele período. Fez-se a soma dos eventos ocorridos em cada ano, pelo raster calculator (ArcGIS 10.1), pixel a pixel, dividindo o produto pelo total de mapas utilizados na série:

$$
I R Q=\frac{Q_{A 1}+Q_{A 2}+Q_{A 3}+\ldots+Q_{A 30}}{n}
$$

onde $Q_{A 1}, Q_{A 2}, Q_{A 3}$ e $Q_{A 30}$ são as queimadas observadas em um pixel, respectivamente, no $1^{\circ}$ ano, $2^{\circ}$ ano, $3^{\circ}$ ano e $30^{\circ}$ ano; $n$ é o número total de anos da série histórica, sendo ele o valor máximo o qual um pixel da série pôde ser atingido por queimadas. Neste caso, a série histórica apresenta $n=30$, considerando que trabalhou-se entre 1984 e 2015 e os anos 2003 e 2012 foram desconsiderados. O mapa resultado mostra valores entre 0 e 1 , visto que quanto mais próximo de 0 , menor recorrência de eventos e quanto mais próximo de 1, maior recorrência.

Buscando evitar a aplicação de limites espaciais entre duas ou mais classes no processo decisório booleano, aplicou-se o processo contínuo Fuzzy, representando o mapa com zonas transitórias e valores da variável distribuídos de forma contínua (FERREIRA, 2014). Utilizou-se a função linear, considerando o valor mínimo do $I R Q$ como 0 e o máximo valor de $I R Q$ como 1.

\subsubsection{Avaliação das queimadas por zonas de planejamento}

Para auxiliar a discussão da distribuição espacial das queimadas no PNSC, consideraram-se três zonas de planejamento: amortecimento (ZA), regularizadas (ZR), não regularizadas (ZNR). Anualmente, geraram-se sub-mapas de queimadas, recortadas pelas três zonas e calcularam-se as áreas dos polígonos de locais queimados para cada uma delas pelo ArcGIS 10.1. Considerou-se como ZR apenas o Chapadão da Canastra, visto que a regularização de trechos do Chapadão da Babilônia foi tardia, após 2013, já no fim da série temporal trabalhada (MESSIAS, 2012).

Os dados de área queimada em cada zona foram tabulados no LibreOffice Calc 5.0, sendo também convertidos em percentual de área queimada por zona. Gerou-se um gráfico de barras a partir desses valores, buscando mostrar quais zonas foram mais afetadas por queimadas. Calculou-se ainda a média $(X)$ e o desvio padrão $(\sigma)$ dos valores, a fim de comparar o regime do fogo nas três zonas.

\section{RESULTADOS E DISCUSSÃO}


A avaliação têmporo-espacial das queimadas no PNSC comprova que a ocorrência do fogo é comum em todo o parque (Figura 2; figura 3). Anualmente, diferentes ambientes são afetados por esses eventos, variando em área, intensidade e local de ocorrência. O regime do fogo é influenciado não só por fatores geoambientais (como declividades, biomassa vegetal, umidade do ar, altitude, orientação das vertentes etc.), como pelo desenvolvimento de atividades antrópicas nas diferentes zonas de planejamento, assim como por restrições de uso. A avaliação de dados quantitativos referentes às queimadas anuais, por zonas de planejamento, possibilitaram-nos compreender essa distribuição (Tabela 2; figura 4).

Todo a área estudada tem aproximadamente $4.674,0 \mathrm{Km}^{2}$, englobando as zonas regularizadas, não regularizadas e de amortecimento, das quais em média $730,14 \mathrm{Km}^{2}$ são queimados todo ano, Este valor mostra que, a cada ano, as zonas de planejamento do parque, em conjunto, têm $15,62 \%$ de sua área atingidas pelo fogo e os dados resultam em um desvio padrão de 6,34. 

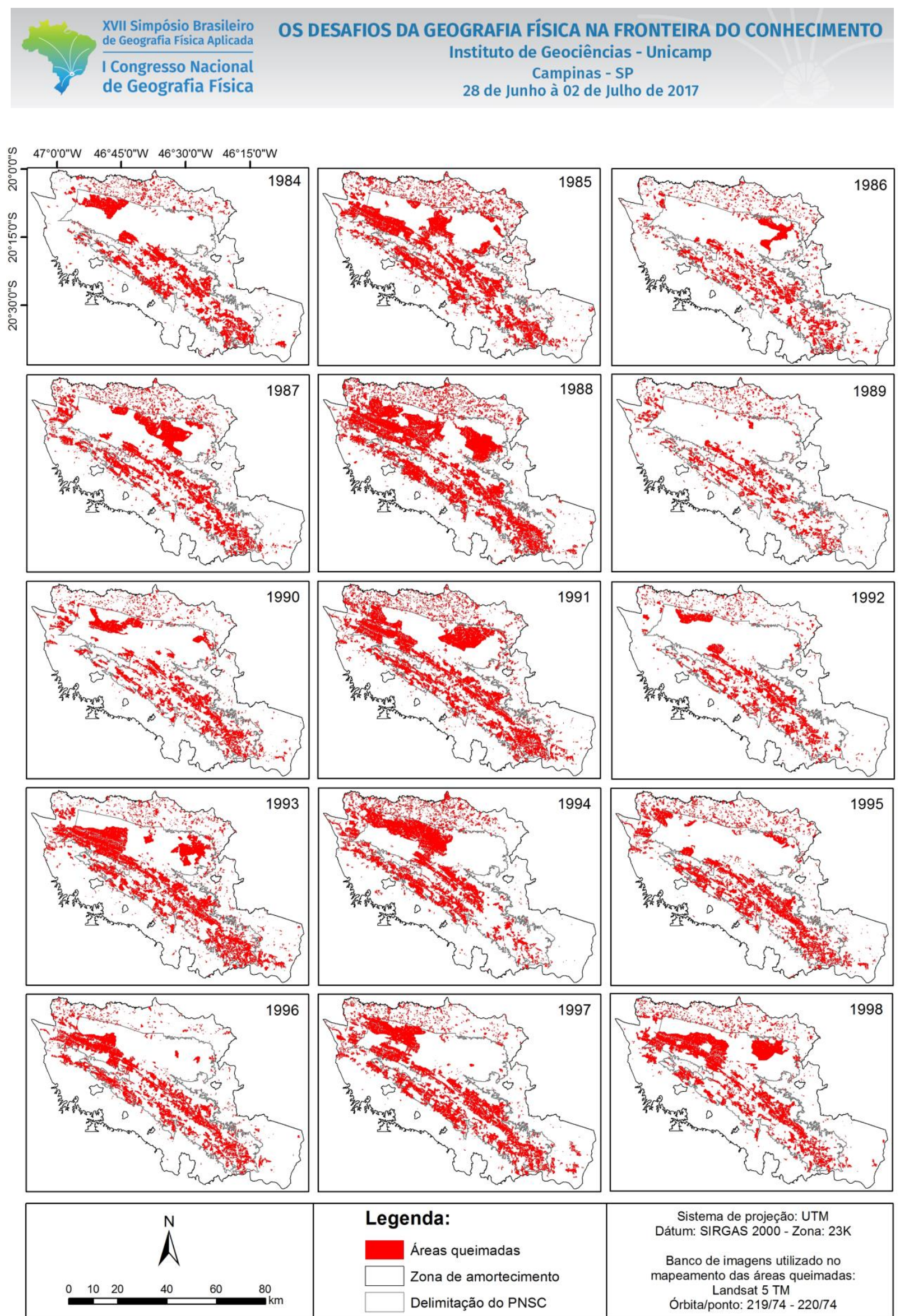

Sistema de projeção: UTM Dátum: SIRGAS 2000 - Zona: 23K

Banco de imagens utilizado no mapeamento das áreas queimadas: Landsat 5 TM

Órbita/ponto: 219/74 - 220/74 

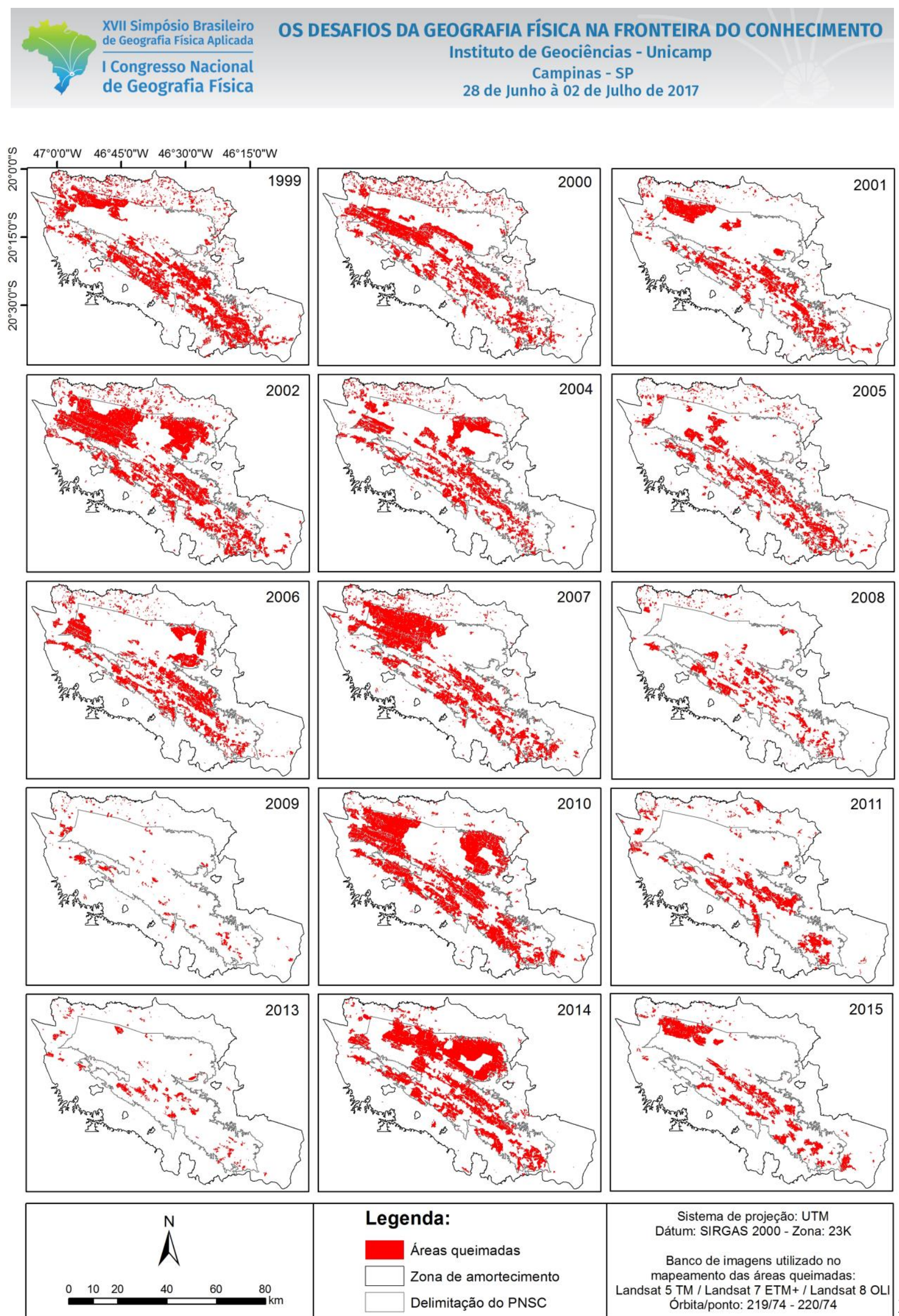

Sistema de projeção: UTM Dátum: SIRGAS 2000 - Zona: $23 \mathrm{~K}$

Banco de imagens utilizado no

mapeamento das áreas queimadas: Landsat 5 TM / Landsat 7 ETM+ / Landsat 8 OLI
Órbita/ponto: $219 / 74-220 / 74$ 


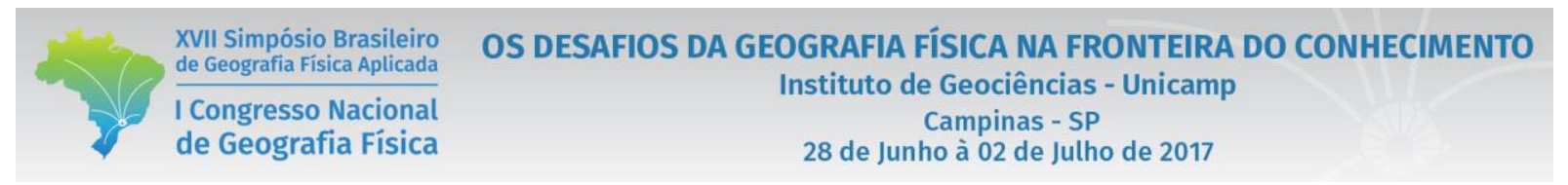

Tabela 2 - Dados quantitativos relacionados às áreas queimadas no PNSC

\begin{tabular}{|c|c|c|c|c|c|c|c|c|}
\hline \multirow[b]{2}{*}{ Ano } & \multicolumn{4}{|c|}{ Área queimada por zona $\left(\mathrm{Km}^{2}\right)$} & \multicolumn{4}{|c|}{ Área queimada por zona (\%) } \\
\hline & $\begin{array}{l}\text { Amorte- } \\
\text { cimento }\end{array}$ & $\begin{array}{c}\text { Não regu- } \\
\text { latizada }\end{array}$ & $\begin{array}{l}\text { Regula- } \\
\text { rizada }\end{array}$ & $\begin{array}{l}\text { Todo o } \\
\text { parque }\end{array}$ & $\begin{array}{l}\text { Amorte- } \\
\text { cimento }\end{array}$ & $\begin{array}{c}\text { Não regu- } \\
\text { latizada }\end{array}$ & $\begin{array}{l}\text { Regula- } \\
\text { rizada }\end{array}$ & $\begin{array}{c}\text { Todo o } \\
\text { parque }\end{array}$ \\
\hline 1984 & 166,99 & 415,58 & 92,27 & 674,84 & 6,19 & 36,15 & 11,14 & 14,44 \\
\hline 1985 & 329,37 & 501,64 & 240,49 & $1.071,50$ & 12,22 & 43,63 & 29,04 & 22,93 \\
\hline 1986 & 176,37 & 358,80 & 75,92 & 611,09 & 6,54 & 31,21 & 9,17 & 13,07 \\
\hline 1987 & 248,66 & 432,76 & 181,21 & 862,64 & 9,22 & 37,64 & 21,88 & 18,46 \\
\hline 1988 & 344,16 & 536,70 & 413,20 & $1.294,06$ & 12,77 & 46,68 & 49,89 & 27,69 \\
\hline 1989 & 149,43 & 303,82 & 8,74 & 461,99 & 5,54 & 26,43 & 1,06 & 9,88 \\
\hline 1990 & 146,76 & 373,73 & 115,48 & 635,98 & 5,44 & 32,51 & 13,94 & 13,61 \\
\hline 1991 & 276,24 & 511,65 & 296,45 & $1.084,34$ & 10,25 & 44,50 & 35,80 & 23,20 \\
\hline 1992 & 105,39 & 345,22 & 58,67 & 509,29 & 3,91 & 30,03 & 7,09 & 10,90 \\
\hline 1993 & 229,55 & 494,48 & 285,23 & $1.009,26$ & 8,51 & 43,01 & 34,44 & 21,59 \\
\hline 1994 & 272,05 & 387,45 & 236,33 & 895,84 & 10,09 & 33,70 & 28,54 & 19,17 \\
\hline 1995 & 232,15 & 455,01 & 57,10 & 744,26 & 8,61 & 39,58 & 6,89 & 15,92 \\
\hline 1996 & 140,77 & 429,02 & 148,60 & 718,39 & 5,22 & 37,32 & 17,94 & 15,37 \\
\hline 1997 & 225,63 & 503,04 & 196,19 & 924,86 & 8,37 & 43,75 & 23,69 & 19,79 \\
\hline 1998 & 177,21 & 366,27 & 288,10 & 831,58 & 6,57 & 31,86 & 34,79 & 17,79 \\
\hline 1999 & 268,79 & 515,24 & 103,43 & 887,46 & 9,97 & 44,81 & 12,49 & 18,99 \\
\hline 2000 & 193,51 & 372,20 & 189,34 & 755,05 & 7,18 & 32,37 & 22,86 & 16,15 \\
\hline 2001 & 87,76 & 343,75 & 138,88 & 570,39 & 3,26 & 29,90 & 16,77 & 12,20 \\
\hline 2002 & 202,13 & 446,84 & 487,25 & $1.136,22$ & 7,50 & 38,87 & 58,84 & 24,31 \\
\hline 2004 & 106,67 & 369,37 & 178,25 & 654,30 & 3,96 & 32,13 & 21,52 & 14,00 \\
\hline 2005 & 110,92 & 359,34 & 67,11 & 537,37 & 4,11 & 31,25 & 8,10 & 11,50 \\
\hline 2006 & 98,62 & 387,27 & 159,68 & 645,57 & 3,66 & 33,68 & 19,28 & 13,81 \\
\hline 2007 & 153,82 & 400,00 & 393,39 & 947,21 & 5,71 & 34,79 & 47,50 & 20,27 \\
\hline 2008 & 50,74 & 225,70 & 9,09 & 285,54 & 1,88 & 19,63 & 1,10 & 6,11 \\
\hline 2009 & 40,86 & 60,36 & 1,66 & 102,87 & 1,52 & 5,25 & 0,20 & 2,20 \\
\hline 2010 & 180,37 & 556,48 & 430,89 & $1.167,74$ & 6,69 & 48,40 & 52,03 & 24,98 \\
\hline 2011 & 85,85 & 286,69 & 4,05 & 376,58 & 3,18 & 24,94 & 0,49 & 8,06 \\
\hline 2013 & 29,11 & 91,84 & 9,80 & 130,74 & 1,08 & 7,99 & 1,18 & 2,80 \\
\hline 2014 & 99,81 & 458,70 & 423,02 & 981,53 & 3,70 & 39,90 & 51,08 & 21,00 \\
\hline 2015 & 44,69 & 232,92 & 118,11 & 395,72 & 1,66 & 20,26 & 14,26 & 8,47 \\
\hline$X$ & 165,81 & 384,06 & 180,26 & 730,14 & 6,15 & 33,41 & 21,77 & 15,62 \\
\hline$\sigma$ & 83,51 & 116,34 & 140,02 & 296,26 & 3,10 & 10,12 & 16,91 & 6,34 \\
\hline
\end{tabular}

Observa-se, avaliando-se individualmente as zonas de planejamento, que os locais não regularizados são onde mais ocorrem incêndios, com uma média de $384,06 \mathrm{Km}^{2}$ queimados ao ano, o que representa 33,41\% da área total. As ZNR estão em grande parte no Chapadão da Babilônia, no perímetro do parque, contudo sem ter sido feita a desapropriação das propriedades particulares nesse local. Verifica- 


\begin{tabular}{|c|c|}
\hline $\begin{array}{l}\text { XVII Simpósio Brasileiro } \\
\text { de Geografia Fisica Aplicada } \\
\end{array}$ & $\begin{array}{l}\text { OS DESAFIOS DA GEOGRAFIA FÍSICA NA FRONTEIRA DO CONHECIMENTO } \\
\text { Instituto de Geociências - Unicamp }\end{array}$ \\
\hline $\begin{array}{l}\text { I Congresso Nacional } \\
\text { de Geografia Física }\end{array}$ & $\begin{array}{l}\text { Campinas - SP } \\
28 \text { de Junho à } 02 \text { de Julho de } 2017\end{array}$ \\
\hline
\end{tabular}

se, nesse ponto, uma falha na gestão do PNSC, visto que a categoria Parque Nacional visa preservar ecossistemas naturais de grande relevância ecológica e beleza cênica e, para isto, as áreas particulares incluídas em seus limites devem ficar sob o domínio público (BRASIL, 2000). 

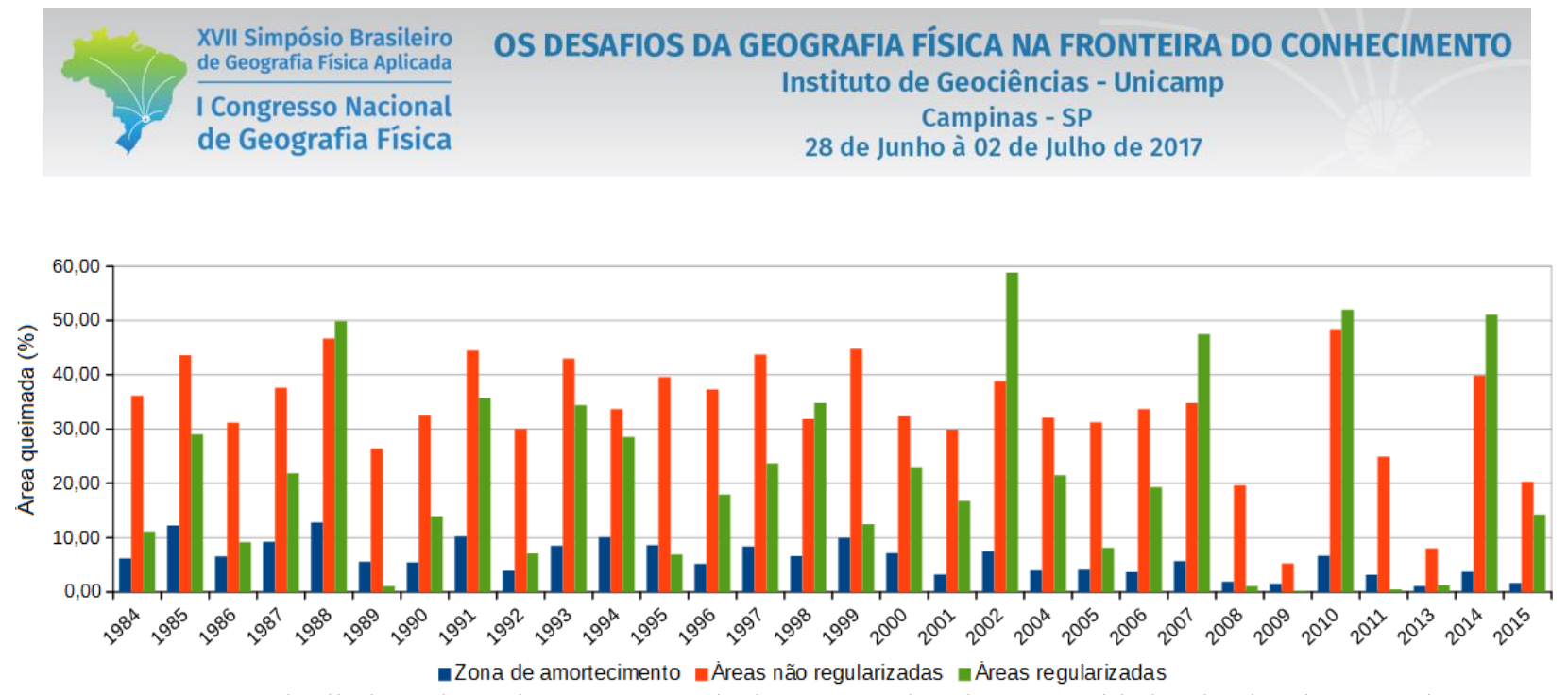

Figura 4 - Distribuição dos valores percentuais de áreas queimadas, por unidades de planejamento do PNSC.

A não regularização desses locais permite o desenvolvimento de atividades conflitantes, tais como agrícolas, mineratórias, pecuária, excesso de estradas e livre acesso (MMA; IBAMA, 2005). Registros mostram que cerca de $50 \%$ das queimadas no parque são de natureza antrópica, maior parte criminosa ou causada pela utilização do fogo como manejo agropecuário de maneira inadequada (MEDEIROS; FIEDLER, 2004). Associado-se a utilização do fogo de forma inapropriada aos geofatores ambientais que propiciam as quaimadas, especialmente nas áreas de maior altitude, as quais apresentam fitofisionomias do cerrado inflamáveis durante o período seco (como por exemplo os campos), médios a altos declives e altas densidades de estradas (MESSIAS, 2014), tornam esses locais vulneráveis às queimadas.

As ZR, localizadas no Chapadão da Canastra, incendiam em média $180,26 \mathrm{Km}^{2}$ ao ano, 21,77\% de sua área. Este valor é menor que o da ZNR, mas está acima da média de todas as zonas de planejamento do parque em conjunto. Isso ocorre pois, apesar de haver restrições de uso do solo, menos estradas de acesso e maior controle do fogo (MMA; IBAMA, 2005), as características geoambientais do local ocasionam a evolução de queimadas, sendo elas semelhantes àquelas das áreas elevadas do Chapadão da Babilônia, anteriormente citadas. Esta afirmação corrobora com estudos que afirmam que campos naturais e ambientes savânicos (como os cerrados) apresentam secas sazonais e devido à presença de gramíneas e fornecem combustível fino abundante próximo ao solo, oxigenado pelo vento (NEPSTAD et al., 1999).

A ZA é a que foi identificada com menor área média anual queimada, de $165,81 \mathrm{Km}^{2}$, o que está associado a 6,15\% da área da zona. Apesar de serem áreas de maior atração populacional, densidade de estradas e desenvolvimento de atividades agropecuárias, este valor, abaixo da média as três zonas, indica que as características físicas desse local, as quais se diferem das áreas do interior do parque, vulnerabilizam, em baixa escala, a ocorrência do fogo. 


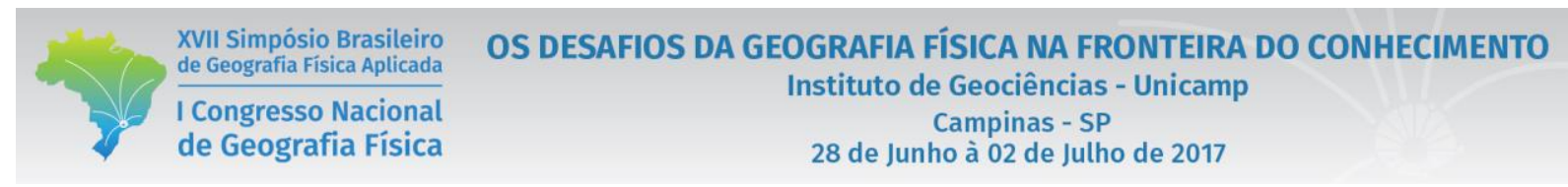

Cabe ainda ressaltar que a ZA apresenta baixo desvio padrão, o que comprova que não há variação significativa nos valores de área queimada ano a ano. $\mathrm{O}$ maior desvio padrão está associado às $\mathrm{ZR}$, que apesar de apresentarem média de áreas queimadas ao ano inferior às $\mathrm{ZNR}$, apresentam maior variação na ocorrência dos eventos. É possível ainda inferir que nas ZR e ZNR ocorrem incêndios com maior intensidade em relação à ZA. Isso ocorre pois as características geoambientais da área interior do parque provocam maior espalhamento do fogo, intensificando as queimadas e gerando polígonos maiores.

O mapa do índice de recorrência de queimadas apresenta a síntese espacial das áreas queimadas

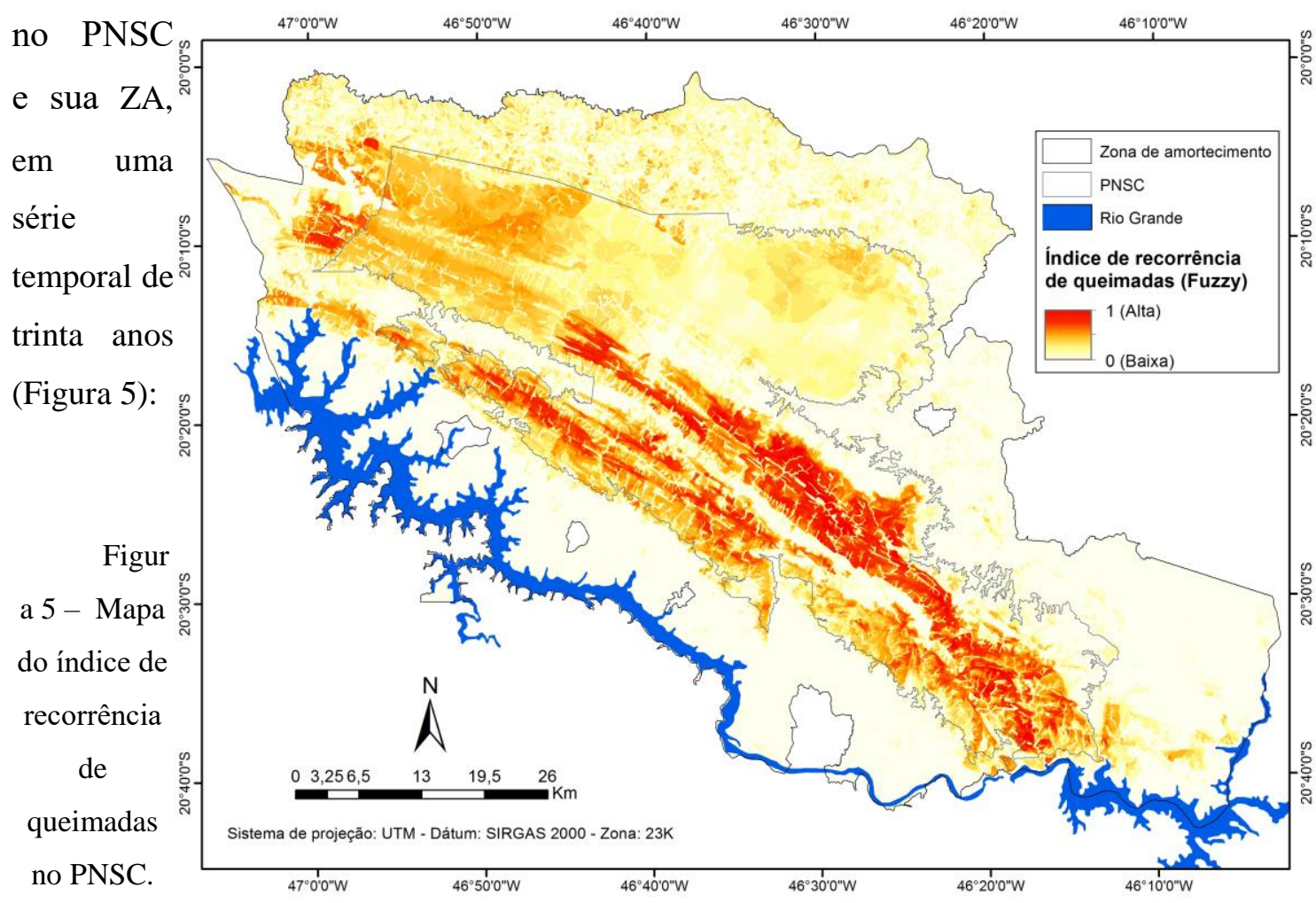

Além de serem os locais com maior média de área queimada ao ano, as ZNR concentram médias e altas recorrências de queimadas, locais nos quais os eventos se repetem constantemente. As ZR apresentam baixos a médios valores de recorrência, comprovando que há um maior controle do fogo. Já na ZA desenvolvem diversas manchas de queimadas todos os anos, mas os baixos IRQ comprovam que as áreas incendiadas variam a cada ano, pois estão associadas à utilização do fogo no manejo agrícola. Nas proximidades do Rio Grande e a leste da ZA ocorrerem atividades agropecuárias, mas pela recorrência 
quase nula percebe-se que fogo não é utilizado como técnica de manejo. Pequenos trechos a Noroeste da ZA apresentam altos e médios IRQ, por apresentam características semelhantes ao parque.

\section{CONCLUSÕES}

1) A cada ano, uma média de $15,62 \%$ de toda a área do PNSC e sua ZA são área atingidas pelo fogo. A zona mais incendiadas trata-se das ZNR, onde, por ano, em média de 33,41\% da área total é queimada; em seguida, têm-se as as ZR, que é atingida por queimadas ao ano em uma média de $21,77 \%$. Por fim, a ZA é a menos queimada, e o fogo está afeta $6,15 \%$ da área ao ano em média.

2) As áreas de maior recorrência de queimadas estão localizadas nas ZNR, que estão situadas no Chapadão da Babilônia. As áreas regularizadas, do Chapadão da Canastra, apresentam médias recorrências. As menores recorrências estão associadas à zona de amortecimento.

3) A utilização de séries temporais de produtos de teledetecção, associados à aplicação de técnicas em SIG, auxiliou-nos na geração de produtos que nos auxiliam na compreensão do regime do fogo nas três Zonas de planejamento do PNSC. A próxima etapa desta pesquisa é compreender como as características geoambientais interferem na ocorrência e no regime do fogo no PNSC.

\section{REFERÊNCIAS BIBLIOGRÁFICAS}

BRASIL. Lei no 9.985, de 18 de julho de 2000. SNUC - Sistema Nacional de Unidades de Conservação.

Publicado no D.O.U. de 19 de julho de 2000.

IBDF. Plano de manejo do Parque Nacional da Serra da Canastra. Brasília: IBDF, 1981

FERREIRA, M.C. Iniciação à análise geoespacial: teoria, técnicas e exemplos para geoprocessamento. SP: Unesp, 2014.

LIMA, G. S. A prevenção de incêndios florestais no estado de Minas Gerais. Floresta, Curitiba, v. 30, n. 1/2, 2000.

LIU, W. T. H. Aplicações de Sensoriamento Remoto. Campo Grande: Ed. UNIDERP, 2006.

MEDEIROS, M. B. M.; FIEDLER, N. C. Incêndios florestais no parque nacional da serra da canastra: desafios para a conservação da biodiversidade. Ciência Florestal, Santa Maria, v. 14, n. 2, p. 157-168, 2004.

MESSIAS, C. G. Mapeamento das Áreas Suscetíveis à Fragilidade Ambiental na Alta Bacia do Rio São

Francisco, Parque Nacional da Serra da Canastra - MG. 13/08/2014. 211 p. Dissertação (mestrado em

Geografia) - Instituto de Geociências, Universidade Estadual de Campinas, Campinas, 2014.

MILLER, J. D.; YOOL, S. R. Mapping forest post-fire canopy consumption in several overstory types using multi- 
temporal Landsat TM and ETM data. Remote Sensing of Environment, v. 83, ed. 2-3, p. 181-496, outubro de 2002.

MISTRY, J.; BIZERRIL, M. Por que é importante entender as inter-relações entre pessoas, fogo e áreas protegidas?

Biodiversidade brasileira, ano I, n. 2, p. 40-49, 2011.

MMA; IBAMA. Plano de Manejo: Parque Nacional da Serra da Canastra. Brasília: MMA, 2005.

NEPSTAD, D. C.; MOREIRA, A. G.; ALENCAR, A. A. Floresta em chamas: origens, impactos e prevenção de fogo na Amazônia. Brasília: Programa Piloto para a Proteção das Florestas Tropicais no Brasil, 1999. 202 p.

PEREIRA, C. A.; FIEDLER, N. C.; MEDEIROS, M. B. Análise de ações de prevenção e combate aos incêndios florestais em Unidades de Conservação do cerrado. Floresta, v. 34, n. 2, Curitiba, p. 95-100, mai/ago 2004.

SUNAR, F; ÖZKAN, C. Forest fire analysis with remote sensing data. International Journal of Remote Sensing, London, v. 22, n. 12, p. 2265-2277, 2001. 